\title{
CuRSo: Diabetes MeLUTtus EN ATENCIÓn PRIMARIA
}

"Desde la prevención a la derivación"

2 y 3 de Abril de 2009. Auditorio Edificio Telefónica. Santiago

Dirigido a:

Organiza:

Médicos, Becados, Enfermeras, Nutricionistas y Equipo de Salud

Presidente:

Sociedad Chilena de Endocrinología y Diabetes

Directores:

Dr. Nelson Wohllk

Informaciones:

Drs. Carmen Gloria Aylwin y Néstor Soto I.

Secretaría SOCHED Fono 2230386.

E mail: soched@soched.cl.www.soched.cl 